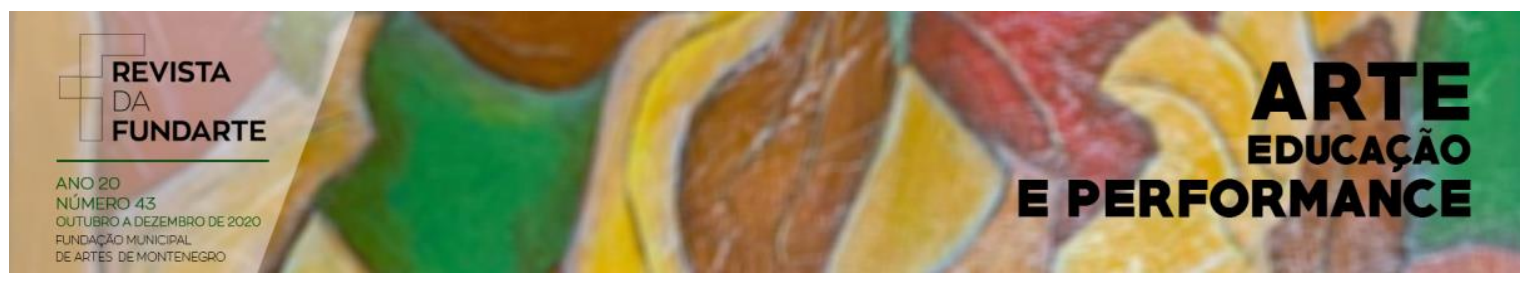

\title{
CRIAÇÃO COLETIVA COMO PRÁTICA PEDAGÓGICA: EXPERIÊNCIAS TEATRAIS NO PERU E NO BRASIL
}

\author{
Marta Haas
}

DOI: http://dx.doi.org/10.19179/2F2319-0868/2F761 


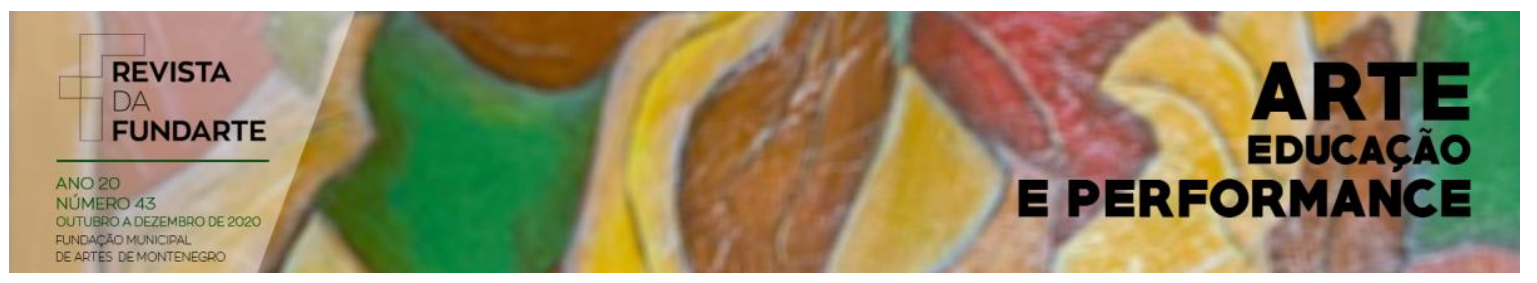

\title{
CRIAÇÃO COLETIVA COMO PRÁTICA PEDAGÓGICA: EXPERIÊNCIAS TEATRAIS NO PERU E NO BRASIL
}

Marta Haas ${ }^{1}$

Resumo: Este artigo discute o processo de criação coletiva nos grupos teatrais latino-americanos Grupo Cultural Yuyachkani (Peru) e Tribo de Atuadores Ói Nóis Aqui Traveiz (Brasil), com suas nuances e diferenças, como espaços de experimentação e de resistência ao pensamento único. Para ambos os grupos, criar coletivamente é uma atitude ética, comprometida com um teatro que seja necessário no tempo e no lugar em que vivemos, constituindo-se como uma prática pedagógica que forma artistas-cidadãos.

Palavras-chave: teatro latino-americano, teatro de grupo, prática artístico-pedagógica.

\section{COLLECTIVE CREATION AS A PEDAGOGICAL PRACTICE: THEATER EXPERIENCES IN PERU AND BRAZIL}

\begin{abstract}
This paper discusses the process of collective creation in the Latin American theater groups Grupo Cultural Yuyachkani (Peru) and Tribo de Atuadores Ói Nóis Aqui Traveiz (Brazil), with its nuances and differences, as spaces for experimentation and of resistance to unique thinking. For both groups, creating collectively is an ethical attitude, committed to a theater that is necessary in the time and place where we live, constituting itself as a pedagogical practice that forms artist-citizens.
\end{abstract}

Keywords: Latin American theater; group theater, artistic-pedagogical practice.

Este texto analisa a prática de criação coletiva em dois grupos latinoamericanos surgidos na década de 1970 e que continuam em plena atividade: o Grupo Cultural Yuyachkani do Peru e a Tribo de Atuadores Ói Nóis Aqui Traveiz do Brasil. Ao falar sobre a prática de criação coletiva que surgiu nos anos 1950 na América Latina, Miguel Rubio Zapata, diretor do Yuyachkani, destaca que o grupo "foi a célula-mãe em que nos organizamos para gerar essa nova teatralidade que reclamávamos aos gritos, e que devia marchar em consonância com os tempos em que se vivia, nos quais predominava um sentimento coletivo" (ZAPATA, 2014, p. 263). A prática da criação coletiva, muito viva nas décadas de 1960 e 1970, tinha o comunitário como compromisso ideológico e a revolução como uma de suas principais causas.

\footnotetext{
1 Doutoranda e Mestra no Programa de Pós-Graduação em Educação da Universidade Federal do Rio Grande do Sul (PPGEDU-UFGRS). Bacharela em Filosofia na UFRGS.
}

HAAS, Marta. Criação coletiva como prática pedagógica: Experiências teatrais no Peru e no Brasil. Revista da FUNDARTE. Montenegro, p.01-19, ano 20, no 43, outubro/dezembro de 2020.

Disponível em: http://.seer.fundarte.rs.gov.br/index.php/revistadafundarte/index> 20 de dezembro de 2020. 


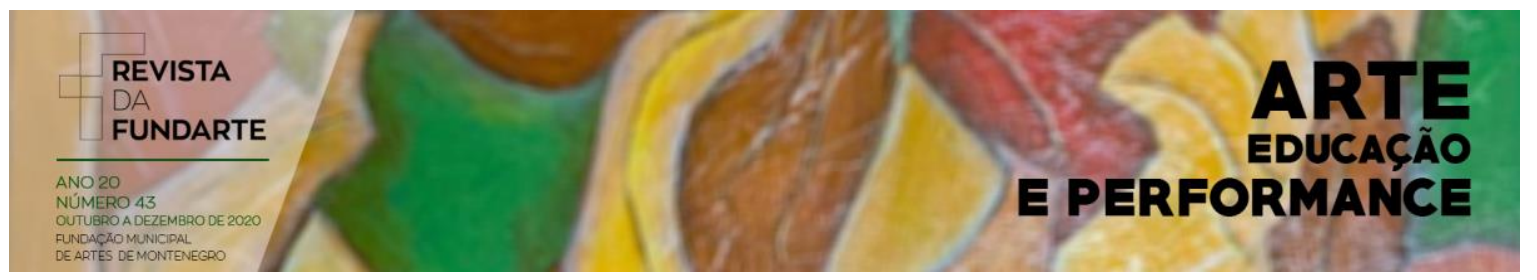

Mesmo depois de tantas mudanças políticas, sociais e artísticas, podemos afirmar que a criação coletiva mantém um compromisso com o comunitário e a transformação social, porém ligada a uma nova forma de poetização da política. $O$ trabalho em grupo, como uma comunidade duradora, abre caminho para a experimentação das linguagens cênicas, reivindicando o lugar do coletivo como espaço de criação e reconstruindo a memória e a história a partir de estruturas mais abertas, fragmentadas, polissêmicas e liminares.

A criação coletiva traz ensinamentos, não só para o campo da pedagogia teatral, mas que extrapolam para o campo da ação cidadã. Formar artistas que estejam atentos ao contexto presente, que denunciem a violência e a injustiça social, são questões urgentes para ambos os grupos. Essa formação implica um trabalho constante, seja externa ou internamente, na busca por transformação. É no encontro com o outro, com o coletivo, que o processo de ação sobre si se revela formador de novas subjetividades. A diversidade de perspectivas e de questionamentos, no ambiente de liberdade que esses coletivos proporcionam, resiste à homogeneização do pensamento.

\section{Atitude ética}

A criação coletiva não é um procedimento de criação com um modelo fixo. Mesmo os grupos latino-americanos surgidos nas décadas de 1950 e 1960 que impulsionaram a ideia de criação coletiva - como os grupos colombianos Teatro Experimental de Cali (TEC), em 1955 e Teatro La Candelaria, em 1966, o cubano Teatro Escambray, em 1968 e o argentino Libre Teatro Libre, em 1969 - possuíam métodos de criação distintos. É evidente, portanto, que existem muitas formas de coletivizar o trabalho de produção teatral. Segundo Stela Fischer (2010, p. 71), "alguns se aproximam muito do que hoje é definido como processo colaborativo, principalmente ao localizar como se estabelecem a organização interna das equipes e os seus modos de produção".

Fischer (2010, p. 72) cita três modos distintos de criação coletiva definidos pelo dramaturgo e diretor peruano Alonso Alegría, para descrever o processo de 


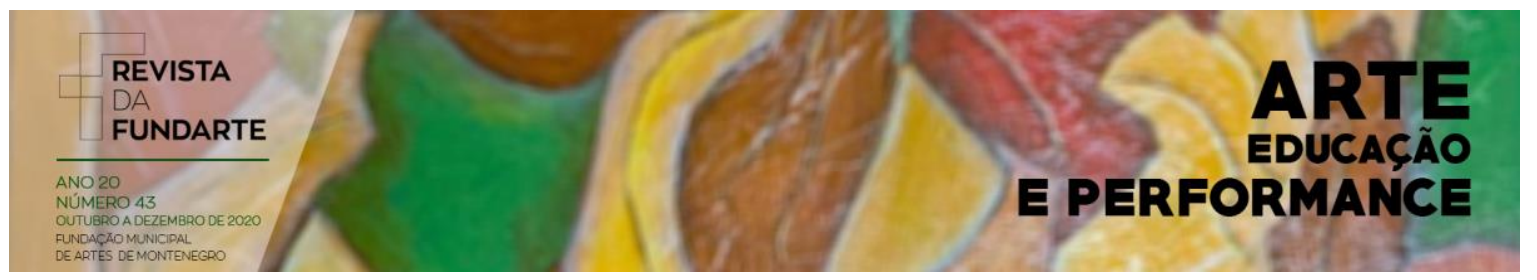

criação na América Latina nas décadas de 1960 e 1970: o primeiro consiste na criação de um espetáculo dirigido coletivamente, a partir de um texto preexistente; o segundo na criação de um texto elaborado coletivamente (ou em um núcleo do próprio grupo), mas com um diretor responsável pela encenação; e o terceiro consiste em criar texto e encenação de forma coletiva e concomitante. Fischer também retoma a distinção realizada por Fernando Peixoto, entre duas possíveis definições da criação coletiva: a primeira parte de uma postura ideológica próxima ou vizinha do anarquismo, que pressupõe a supressão de um chefe, diretor ou autor, para que todo o grupo participe igualmente no processo criativo; já a segunda definição pressupõe uma participação íntegra e essencial de todos no processo de criação, porém mantém as figuras do diretor ou autor como organizadores ou coordenadores de uma vontade coletiva.

Se levarmos em conta essas distinções, conseguimos situar melhor o modo de trabalho do grupo Yuyachkani fundado em 1971 e do Ói Nóis Aqui Traveiz fundado em 1978. O grupo peruano mantém a figura do diretor, Miguel Rubio Zapata, que cumpre essa função de organizar e catalisar a vontade do coletivo. A dramaturgia dos espetáculos, na maior parte das vezes, é construída coletivamente durante o processo criativo. Por sua vez, o grupo brasileiro trabalha com a ideia de autogestão, na qual não existe a figura de um diretor ou dramaturgo. Ao afirmar sua opção, o Ói Nóis costuma frisar que direção coletiva não significa que não haja direção, mas que ela é exercida por diversas pessoas, pois todos os atuadores são instigados a exercer a função do olhar de fora e de organizar o material criativo. Para sintetizar essa ideia, utiliza-se a noção de ator-encenador. Ao mesmo tempo, trabalha-se, tanto com uma dramaturgia construída coletivamente durante 0 processo, como com um texto teatral que já existe previamente e que é retrabalhado no processo.

Essas distintas formas de trabalhar coletivamente refletem uma distinção que já existia na década de 1970 entre os grupos brasileiros e grupos dos demais países latino-americanos. Os grupos brasileiros pretendiam suprimir a separação entre as diversas funções teatrais. Isso é ressaltado por Sílvia Fernandes, ao analisar o 


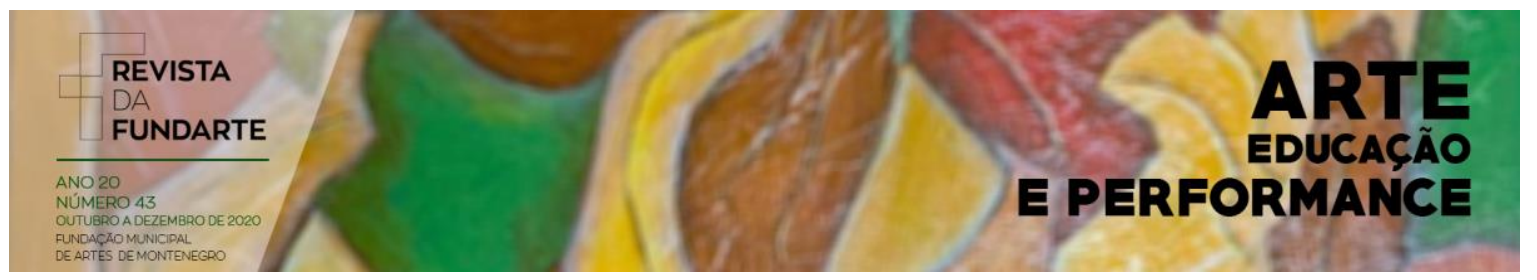

processo coletivo de alguns grupos brasileiros na década de 1970, principalmente aqueles que buscavam, por meio da investigação e experimentação, novos modos de criação:

havia uma diluição da divisão rígida entre funções artísticas e a uma democrática repartição das tarefas práticas. Todos os participantes eram autores, cenógrafos, figurinistas, iluminadores, sonoplastas e produtores dos espetáculos. Era evidente a intenção de fazer dos trabalhos o fruto da colaboração de cada participante. (FERNANDES, 2000, p.14).

Os grupos focavam-se na figura do ator e na função da atuação, para criar coletivamente todos os elementos que fazem parte de uma encenação (direção, dramaturgia, cenografia, figurino). Ainda segundo Fernandes (1998, p. 16), "todo processo criativo gira em torno do ator, ou de uma função que se pode chamar de atuação, onde os participantes da equipe são responsáveis pela criação de todos os elementos da cena". Os grupos latino-americanos, no entanto, como o próprio TEC da Colômbia, precursor do método de criação coletiva, mantinham funções bem definidas nos grupos. $O$ que eles pretendiam era extinguir a autoridade do diretor $\mathrm{e}$ instaurar processos em que todas as funções dialogassem de forma horizontal e democrática. Segundo Beatriz Rizk,

tratava-se de escrever obras (posto que não as havia) sob a perspectiva do segmento majoritário, ou seja, das classes desfavorecidas, e levá-las à cena de uma forma realmente democrática suprimindo a hierarquização das tradicionais companhias de teatro, quase sempre funcionando por meio do produtor, o dono do espetáculo, que fazia suas opções conforme um sistema de "estrelas".(RIZK, 2008, p. 118, tradução minha).

É importante frisar, no entanto, que em ambos os grupos, Ói Nóis e Yuyachkani, a escolha por trabalhar com a criação coletiva é uma atitude antes de tudo ética. Ao analisar as diferenças entre as criações coletivas de grupos surgidos nas décadas entre 1960 e 1970 e o processo colaborativo de grupos brasileiros surgidos a partir dos anos 1990, Stela Fischer aponta que, além da evidente passagem de tempo que as separam, há uma tendência maior à especialização das funções no processo colaborativo. Segundo Antônio Araújo (2009, p. 48), diretor do Teatro da Vertigem, o processo colaborativo "constitui-se numa metodologia de criação em que todos os integrantes, a partir de suas funções artísticas específicas,

HAAS, Marta. Criação coletiva como prática pedagógica: Experiências teatrais no Peru e no Brasil. Revista da FUNDARTE. Montenegro, p.01-19, ano 20, no 43, outubro/dezembro de 2020.

Disponível em: http://.seer.fundarte.rs.gov.br/index.php/revistadafundarte/index> 20 de dezembro de 2020. 


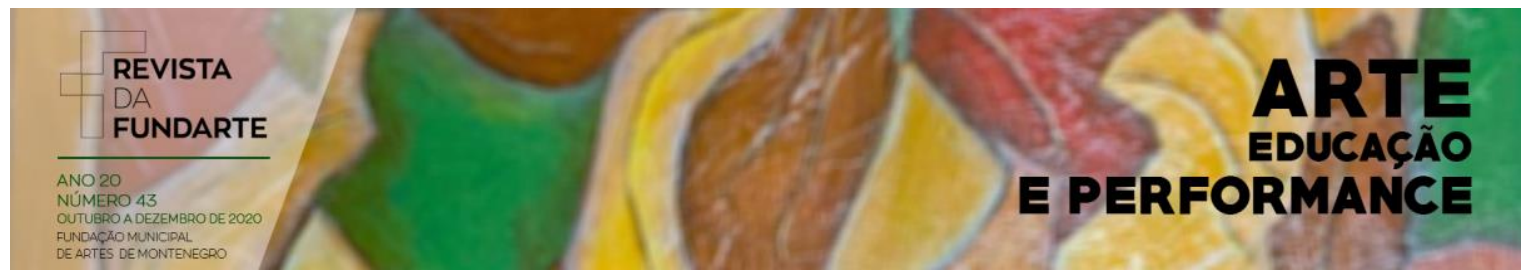

têm igual espaço propositivo, produzindo uma obra cuja autoria é compartilhada por todos". Sua dinâmica não representaria uma ausência de hierarquias, mas um sistema de hierarquias momentâneas ou flutuantes, que se localizam em determinado campo da criação para em seguida mover-se para outro. Para Stela Fischer, porém, a principal distinção entre os procedimentos coletivos e colaborativos está em uma postura no campo ideológico.

É qualidade da prática de grupos de criação coletiva dos anos 1960 e 1970, uma motivação no campo ideológico, uma conduta de ruptura e questionamentos de padrões e comportamentos, uma predisposição para explorações nos campos corporais e sensoriais, enfim, um maior engajamento que moveu ou ainda move pessoas a se agruparem em torno de um projeto comum e comunitário peculiares à época. Alguns grupos que ainda se definem como criação coletiva mantêm, de alguma forma, essa postura política diante do seu meio. (FISCHER, 2010, p. 73).

Essa postura ideológica reverbera no processo de criação, nas atividades pedagógicas e no posicionamento como cidadão. Ambos os grupos aqui analisados possuem um posicionamento político que extrapola o fazer teatral. Ao falar sobre a organização e gestão do Ói Nóis, Paulo Flores evidencia o quanto a ideologia libertária atravessa o trabalho do grupo.

Estamos apostando em uma utopia de como o socialismo se constrói na prática. Isso é fundamental. Por isso nos definimos como um grupo anarquista que perpassa todo o nosso trabalho. Existe uma direção bem clara que é a ideologia do grupo. O condutor é a ideologia libertária. Isso é determinante de toda a maneira de organização e administração do grupo. (apud FISCHER, 2010, p. 83).

De modo semelhante, Miguel Rubio fala o quanto foi importante para a geração do Yuyachkani possuir uma ideologia na qual pudessem acreditar, que fosse motor da luta por transformação, e reafirma o compromisso do grupo com essa luta.

\begin{abstract}
Reconheço que existe em nosso meio uma grande crise ideológica. As pessoas não têm em que acreditar. Eu sou de uma geração em que acreditar era muito importante, sabíamos em que apostávamos, qual era o sonho de amanhã e porque lutávamos. Creio que nesse caos ideológico há muitas pessoas que perderam a memória facilmente e esqueceram o que se construiu nesses anos no Peru e na América Latina. Creio que o socialismo serviu muito para pensar a história e para que as coisas não sigam sendo iguais em todos nossos países. Nós nos reafirmamos nessa teimosia de seguir apostando no socialismo. (ZAPATA, 2001, p. 108-109, tradução minha).
\end{abstract}

HAAS, Marta. Criação coletiva como prática pedagógica: Experiências teatrais no Peru e no Brasil. Revista da FUNDARTE. Montenegro, p.01-19, ano 20, no 43, outubro/dezembro de 2020.

Disponível em: http://.seer.fundarte.rs.gov.br/index.php/revistadafundarte/index> 20 de dezembro de 2020. 


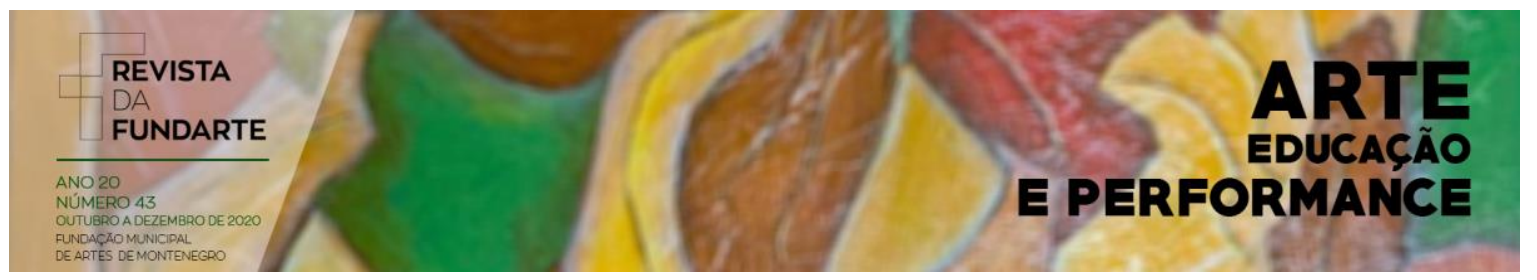

Zapata descreve três elementos que considera fundamentais na criação coletiva: "o teatro de grupo; a dramaturgia coletiva; e a cultura do ator, que tem na improvisação a ferramenta fundamental para enfrentar o processo criativo" (2008, p. 20, tradução minha). Para o diretor, o grupo não apenas guarda a experiência, mas faz dela uma reflexão cotidiana, que the permite sistematizar um processo de trabalho caracterizado pela invenção do espetáculo e a criação ativa de sua própria dramaturgia. O grupo faz sua unidade transcender o espetáculo e gera novos vínculos entre seus integrantes. Por isso, os grupos são impulsores de correntes artísticas cuja obra merece ser analisada em conjunto. Sua estrutura orgânica não é regida pelas leis de mercado, mas por um anseio comum: "os grupos tendem a ser uma expressão democrática de um objetivo a cujo serviço está a organização do mesmo" (ZAPATA, 2001, p. 34, tradução minha). Nos grupos, se estabelecem relações mais horizontais e seus integrantes participam de todo o processo criativo: desde a escolha do tema até a montagem de um espetáculo, passando pela produção e distribuição de tarefas técnicas necessárias para a sua realização.

Outro elemento importante é a dramaturgia coletiva, que trouxe outras possibilidades de escrita no espaço, para além da literatura dramática. Ela possibilita desfazer certezas, incorporar saberes, encontrar matizes que tornam mais complexa a escritura cênica. A dramaturgia coletiva tem a improvisação como ferramenta fundamental para levantar material e transformá-lo em ação dramática. Improvisar permite criar uma escritura no espaço e não só encontrar uma rota que leve a um texto literário, onde muitas vezes os processos de investigação terminam. Segundo Zapata (2008), o Yuyachkani usa o termo "acumulação sensível" para denominar o espaço no qual os atores podem aproximar-se do tema abordado em determinada obra abrindo sua sensibilidade para o que está colocado, usando as associações que the venham à mente no momento. Surge a partir do jogo, e o resultado é depois analisado para saber se tem lugar no processo de composição ou aproximação do tema trabalhado. Sob uma perspectiva histórica, a obra dramatúrgica do Yuyachkani

HAAS, Marta. Criação coletiva como prática pedagógica: Experiências teatrais no Peru e no Brasil. Revista da FUNDARTE. Montenegro, p.01-19, ano 20, no 43, outubro/dezembro de 2020.

Disponível em: http://.seer.fundarte.rs.gov.br/index.php/revistadafundarte/index $>20$ de dezembro de 2020. 


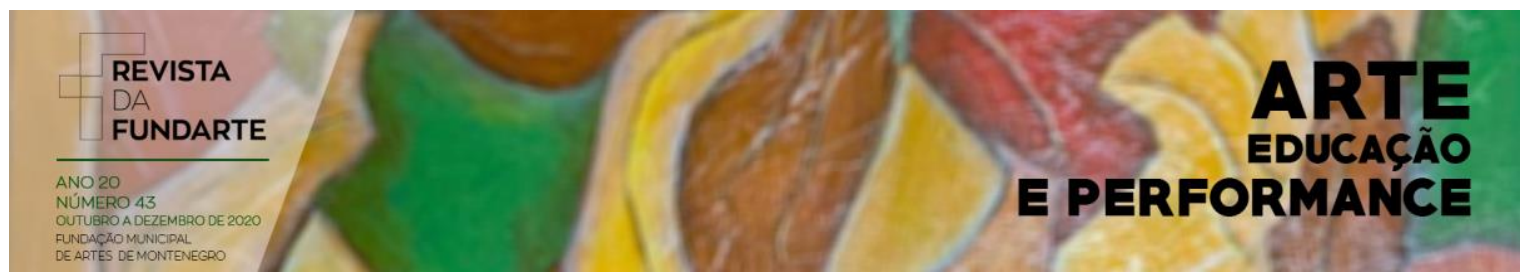

pode ser lida em paralelo com momentos importantes da realidade política e social do Peru,

porque nos interessou dialogar com nosso tempo e propor um teatro crítico, inconformado. A dinâmica política, social e artística assim demanda, ao viver em um país convulsionado pela violência, a corrupção e o atropelo permanente dos direitos sociais, econômicos e culturais mais elementares. Desde o princípio, nossas criações coletivas transitaram por texturas dramáticas muito diversas e caminhos derivados do diálogo com nossos espectadores. (ZAPATA, 2008, p. 23, tradução minha).

A ideia de cultura do ator diz respeito à importância dada ao ator como criador que se responsabiliza por sua criação, pelo que diz e faz em cena. É uma atorcriador que gera material e o coloca a serviço da obra. Para chegar ao estado físico e mental que a cena demanda, é necessário um longo processo de trabalho e treinamento. Zapata afirma que a "presença poderia ser o fio condutor e a palavrachave para assinalar o caminho de aprendizagem que nossos atores seguiram desde o início; um caminho que teve acentos e particularidades de acordo com nossa vida em grupo" (2008, p. 26, tradução minha). Quando requisitado por jovens atores, que vêm em busca de receitas e métodos,

\begin{abstract}
é sempre necessário repetir que a criação coletiva não é uma fórmula e não supõe necessariamente um método. Então, nós temos que explicar que é mais uma atitude aberta à proposta, uma disposição para se confrontar sentindo o outro, um exercício de admiração e de constante mudança. Portanto, não podemos reduzir a criação coletiva à técnica ou às técnicas de criação, nem ignorar sua origem. Seus motivos iniciais têm mais a ver com ética do que com estética, com o desejo de agir sobre a vida social, a intervir conscientemente em nosso tempo. (ZAPATA, 2008, p. 20, tradução minha).
\end{abstract}

Essa postura de criar um teatro que se faça necessário, que seja um diálogo entre artistas comprometidos com o contexto social em que estão inseridos, constitui uma atitude ética presente também no trabalho da Tribo de Atuadores,e na própria ideia de "atuação" que o grupo propõe, como veremos a seguir. Cabe ressaltar aqui que esses três elementos que Miguel Rubio considera fundamentais na criação coletiva - o teatro de grupo, a dramaturgia coletiva e a cultura do ator - são elementos que impedem a cristalização de um pensamento único e homogêneo e que instigam a diversidade de saberes e experiências.

HAAS, Marta. Criação coletiva como prática pedagógica: Experiências teatrais no Peru e no Brasil. Revista da FUNDARTE. Montenegro, p.01-19, ano 20, no 43, outubro/dezembro de 2020.

Disponível em: http://.seer.fundarte.rs.gov.br/index.php/revistadafundarte/index $>20$ de dezembro de 2020. 


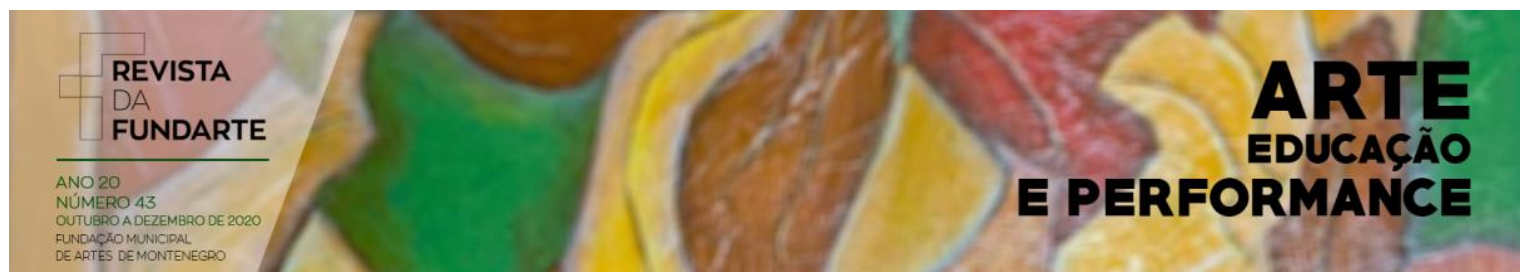

\title{
Pedagogia do coletivo: formar artistas-cidadãos
}

Em ambos os grupos, a ideia de criar coletivamente extrapola, não só para o campo da pedagogia teatral, mas também para o campo do ativismo político. $O$ Yuyachkani, por exemplo, possui um trabalho pedagógico que relaciona teatro e comunidade, no qual organiza um trabalho social organizado em três eixos fundamentais: cidadania, gênero e identidade/memória. Ao falar sobre o trabalho do grupo com comunidades do interior do país, Zapata afirma:

[...] nós somos uma coletividade que não se define só por seus espetáculos. [...] $\mathrm{Na}$ medida de nossas possibilidades, fazemos esse trabalho de extensão, para compartilhar não só com pessoas que se dedicarão ao teatro, mas com pessoas que fazem uso do teatro para fins de sua comunidade e também para instigar vocação nos oficinandos. (2001, p. 109, tradução minha).

A própria Casa Yuyachkani, sede do coletivo, é um centro cultural concebido para e em direção à comunidade, aberto à experimentação, difusão e promoção de expressões culturais e artísticas multidisciplinares. Seus integrantes compartilham sua experiência por meio de oficinas formativas, que evidenciam seu compromisso como cidadãos e buscam cooperar com diversas organizações sociais, iniciativas solidárias e instituições.

\begin{abstract}
A relação do Yuyachkani com os diferentes setores sociais busca abrir reflexões maiores e mais profundas nas quais a pessoa passe a ser protagonista e a posicionar-se em relação aos fatos. Então podemos afirmar que, nesse campo, as atividades do Yuyachkani são uma proposta de educação pela arte. No entanto, não se trata tanto de uma obra pedagógica, com uma mensagem fechada, que pretenda impor-se a seu interlocutor, o diferencial é o de transmitir vivências mais que transmitir ideais. (GRUPO CULTURAL YUYACHKANI, 2015, n.p., tradução minha).
\end{abstract}

Nas ações pedagógicas destinadas a um público que não necessariamente se dedicará ao teatro, o mais importante é proporcionar momentos em que cada indivíduo possa posicionar-se de forma autônoma com relação à sua realidade. Não existem ideias e mensagens prontas a serem aprendidas, mas se proporciona a abertura para a reflexão, a partir da própria vivência artística. Nesse caso, é muito evidente o compromisso ético dos integrantes do grupo com relação aos diferentes setores sociais, e a importância dada a uma formação cidadã. Mas também nos

HAAS, Marta. Criação coletiva como prática pedagógica: Experiências teatrais no Peru e no Brasil. Revista da FUNDARTE. Montenegro, p.01-19, ano 20, oㅡ 43, outubro/dezembro de 2020.

Disponível em: http://.seer.fundarte.rs.gov.br/index.php/revistadafundarte/index $>20$ de dezembro de 2020. 


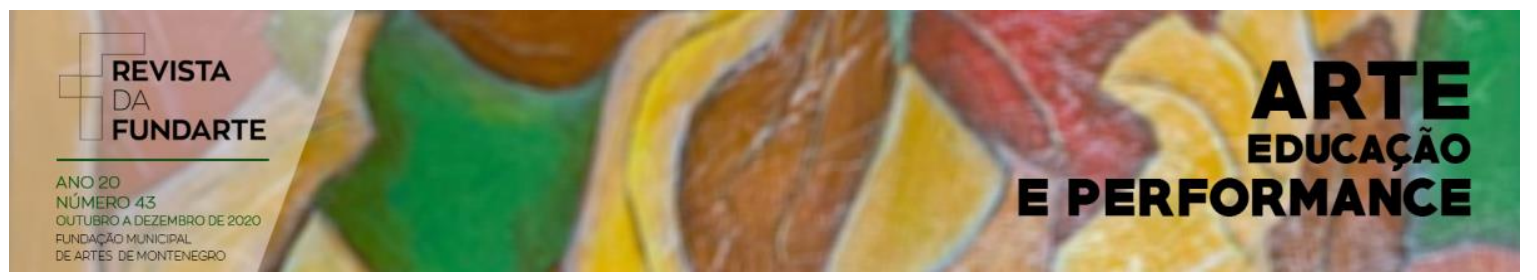

Laboratórios Abertos, destinados a artistas e pesquisadores de teatro, a necessidade de uma formação cidadã fica evidente.

Desde 2009, os Laboratórios Abertos são realizados anualmente na Casa Yuyachakani e desenvolvidos de maneira intensiva, geralmente durante oito dias de trabalho. Inclui experiências práticas e teóricas, com sessões de treinamento, oficinas, demonstrações, desmontagens, conferências e algumas obras do repertório. Nesses encontros, os integrantes compartilham sua própria formação teatral e a experiência como coletivo. Para os interessados, ressaltam que a técnica não deve ser entendida como uma lista de fórmulas, ou maneiras estáticas válidas para sempre, mas como ferramentas. No laboratório, mostram as ferramentas utilizadas para tentar responder as perguntas surgidas em diferentes processos, entendendo o teatro como uma construção cultural e não um cânon definitivo:

Ao longo desses anos tentamos fazer com que nosso lugar de criação cotidiana seja um espaço de liberdade [...]. Entendemos por laboratório esse espaço de necessária e curiosa indagação, no qual nos formamos e que tem dado sentido a tantos anos reunidos em torno da criação. Isso nos permitiu realizar propostas cênicas em que nos sentimos refletidos. Ao mesmo tempo, esses processos criativos nos permitiram construir um suporte técnico grupal e caminhos pessoais, escutando o que nossos velhos mestres nos ensinaram: aprender a aprender para inventarmos 0 teatro que nos faz falta. (GRUPO CULTURAL YUYACHKANI, 2015, n.p., tradução minha).

É importante ressaltar que o Yuyachkani é um grupo com elenco estável, e a maior parte dos seus membros permanece junto, há pelo menos trinta e cinco anos. Não houve um momento em que decidiram ser um grupo fechado a novos participantes, mas conforme foi sendo construída a sua trajetória, hoje não há preocupação em incorporar novos integrantes. A preocupação maior, em seus espaços pedagógicos, é a de incentivar jovens artistas, a partir da difusão de seu próprio trabalho e história, a reconhecerem quais são as necessidades atuais do fazer teatral. O processo de compartilhar ferramentas que foram úteis ao grupo não impõe um modelo ou estética teatral, mas é sempre acompanhado de uma "reflexão sobre o país e sobre a ética como teatristas, para finalmente deixar-lhes escolher por suas próprias opções" (ZAPATA, 2001, p. 110, tradução minha).

HAAS, Marta. Criação coletiva como prática pedagógica: Experiências teatrais no Peru e no Brasil. Revista da FUNDARTE. Montenegro, p.01-19, ano 20, no 43, outubro/dezembro de 2020.

Disponível em: http://.seer.fundarte.rs.gov.br/index.php/revistadafundarte/index> 20 de dezembro de 2020. 


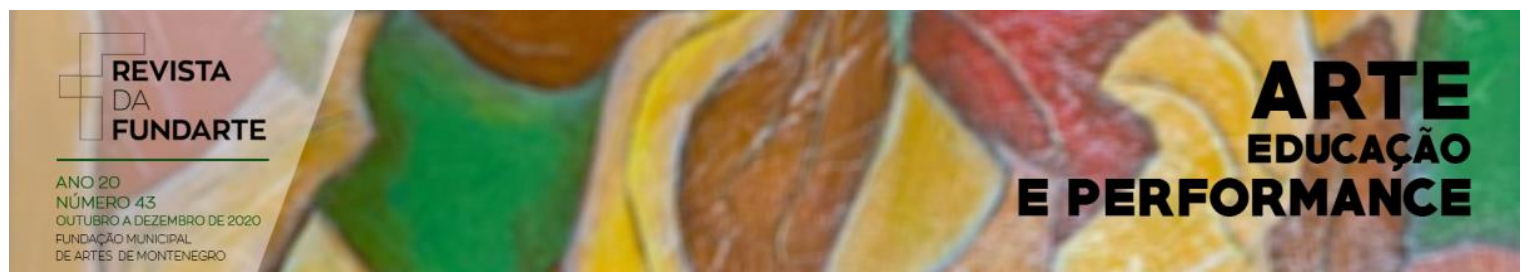

A Tribo de Atuadores Ói Nóis Aqui Traveiz, por sua vez, desde sua origem, é um grupo aberto a novos participantes. Em cada nova montagem, fazem parte do processo de criação pessoas com experiências muito diversas. A diversidade de experiências deve-se, em primeiro lugar, ao fato de que sempre existem pessoas que participam pela primeira vez de um processo de criação no grupo. Em geral, essas pessoas são oriundas das diversas oficinas ministradas em sua sede, ou em bairros periféricos da região metropolitana de Porto Alegre. A diversidade de experiências também está num plano geracional, pois sempre há pessoas muito jovens compartilhando o processo.

O fluxo de entrada e saída dos integrantes do grupo faz parte da dinâmica do Ói Nóis, devido a diversos fatores, inclusive de divergência com relação ao modo e proposta de trabalho. Um dos principais fatores que levam à saída de integrantes, no entanto, é o fator econômico. O grupo exige uma dedicação muito grande de tempo e empenho, independente do retorno financeiro, como explica Paulo Flores:

sabemos que o trabalho do grupo é intenso, difícil no sentido da sobrevivência, que exige muito das pessoas e que não está em primeiro plano a sobrevivência do indivíduo. Colocamos que em primeiro lugar está a sobrevivência da ideia, do espaço para que essa ideia aconteça e, depois, a sobrevivência das pessoas. Essa foi a maneira que encontramos desde as épocas mais difíceis até hoje. (apud FISCHER, 2008, p. 81).

Para manter-se coerente com suas ideias, o Ói Nóis abriu mão de um elenco permanente e fixo. $\mathrm{O}$ grande fluxo de entrada e saída de pessoas poderia implicar em uma perda de memória e identidade para o coletivo, porém uma das formas encontradas para não se perder a experiência e acumular conhecimento e aprendizado é personificada na ideia do "atuador".

O termo "atuador" foi cunhado pelo Teatro Oficina na década de 1970, momento em que o grupo paulista leva ao limite a concepção de que o fenômeno teatral nasce e se concentra na coautoria entre ator e público, apropriando-se da ideia de que "não atuamos, nós somos" (SILVA, 2002, p. 125). A proposta era levar às últimas consequências a fusão entre arte e vida, rompendo barreiras entre palco e plateia,

engendrando-se um conjunto de atuadores que, num jogo criativo, despido

HAAS, Marta. Criação coletiva como prática pedagógica: Experiências teatrais no Peru e no Brasil. Revista da FUNDARTE. Montenegro, p.01-19, ano 20, no 43, outubro/dezembro de 2020.

Disponível em: http://.seer.fundarte.rs.gov.br/index.php/revistadafundarte/index $>20$ de dezembro de 2020. 


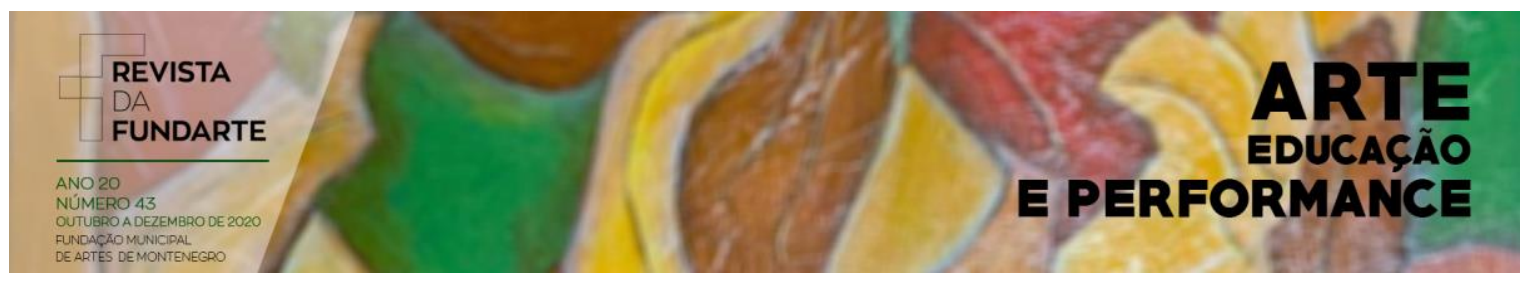

de máscara, promoveriam a comunicação e a liberdade coletiva. A coparticipação, que sempre fora entendida no teatro como um fator de apoio, passaria a ser real coautoria em ação, ou seja, atuação. O atuador seria o instigador de novos comportamentos individuais e sociais... A vida renovada pela arte. (SILVA, 2002, p. 125).

Esses ideais ganharam sua mais sensível expressão em Gracias, Señor (1972), espetáculo crucial para a trajetória do Oficina. O título remete a uma expressão de comportamento subserviente do latino-americano subdesenvolvido diante do poder imperialista. Segundo seus criadores, deve ser encarado não como uma catarse libertária, mas como um código de redimensionamento de papéis sociais. Não mais teatro, mas te-ato; menos representação e mais ação. Por um lado, o espetáculo marca a ruptura do grupo com a forma de organização empresarial; por outro, questiona as relações entre atores e espectadores entendida como uma metáfora das relações sociais de opressão. O teatro torna-se possibilidade de ação transformadora coletiva.

Gracias, Señor foi não só uma resposta brasileira aos desafios propostos pelo Living Theatre na equação teatro e vida, como também inaugurou, no Brasil, uma forma nova de produção teatral que vai, de diferentes modos, repercutir amplamente nos procedimentos estéticos e éticos dos grupos vindouros. (RAMOS, 2005, p. 115).

No início dos anos 1980, época de retomada das grandes manifestações sociais pós-ditadura militar, o grupo Ói Nóis Aqui Traveiz toma para si o termo atuador. Inspirado pelos relatos das experiências do Living Theatre e do Teatro Oficina, desenvolve e dá outras conotações a essa ideia. Para o coletivo, o atuador é a junção do artista com o ativista político, ou seja, sua atuação não se reduz à cena, mas é ampliada: é preciso adotar um posicionamento engajado socialmente e comprometer-se com a realidade que nos cerca. A partir de um posicionamento ético consigo mesmo, surge um teatro comprometido eticamente com seu público, em que o mais importante é a relação entre os seres humanos.

O projeto do Ói Nóis, portanto, não se localiza apenas na cena, mas na construção de uma nova sociedade, o que faz com que o grupo também coloque a formação do cidadão lado a lado com a formação do ator. É importante ressaltar que, desde sua origem, o grupo buscou compartilhar suas experiências e

HAAS, Marta. Criação coletiva como prática pedagógica: Experiências teatrais no Peru e no Brasil. Revista da FUNDARTE. Montenegro, p.01-19, ano 20, no 43, outubro/dezembro de 2020.

Disponível em: http://.seer.fundarte.rs.gov.br/index.php/revistadafundarte/index $>20$ de dezembro de 2020. 


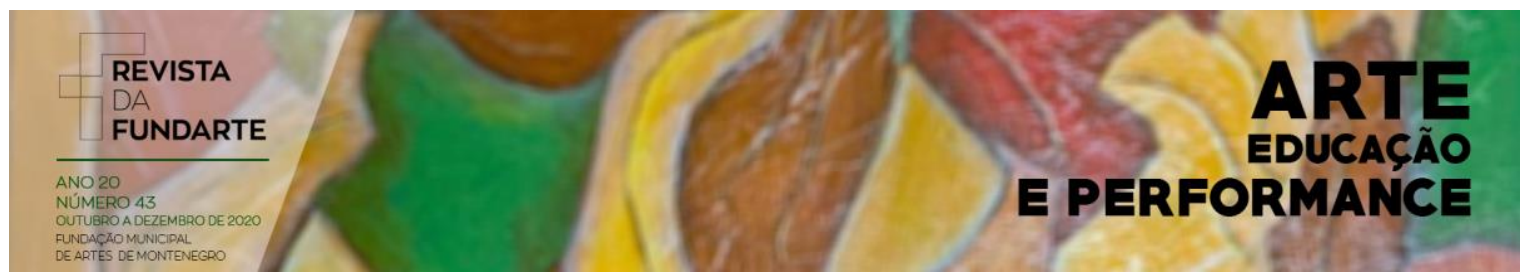

descobertas. É a vontade de ampliar seus conhecimentos por meio da troca com outras pessoas que dá origem à sua vertente pedagógica. A partir de 1984 - com a criação da Terreira da Tribo, o centro de criação e experimentação do grupo - são mantidas diversas oficinas oferecidas gratuitamente à comunidade. Em 2000, com uma intensa produção teatral e uma vasta experiência de trabalho pedagógico na formação de novos atores, o Ói Nóis cria a Escola de Teatro Popular, que oferece para a cidade oficinas de iniciação teatral, pesquisa de linguagem, formação e treinamento de atores, mostra de processos pedagógicos, além de seminários e ciclos de discussão sobre as artes cênicas, consolidando a ideia de uma aprendizagem solidária. A formação que essa Escola pretende proporcionar aos seus alunos não é rigorosa apenas do ponto de vista da técnica, mas principalmente, no tocante à construção de uma ética, que se refere, não apenas ao exercício da profissão de ator, mas ao seu papel social, que requer um comprometimento com a realidade que o cerca. Os oficinandos são constantemente incentivados a trabalhar coletivamente. Dessa forma, processos que poderiam ser individuais, como os de construção de personagens, transformam-se numa vivência coletiva de experiências partilhadas e construção conjunta de sentidos.

Ao pesquisar a autogestão no grupo, Vecchio (2007) percebeu que a dinâmica do Ói Nóis Aqui Traveiz pressupõe efetivamente mudanças de postura, que levam os atuadores (oficinandos e oficineiros em processo de aprendizagem) a se reelaborarem como sujeitos e transformarem a si mesmos. Isso foi percebido em distintos âmbitos:

a consciência política - a compreensão dos mecanismos de opressão de uma sociedade dividida em classes, e a escolha em assumir uma postura crítica perante tal realidade;

a liberdade como valor - o reconhecimento de que a manifestação de cada integrante contribui ao andamento autogestionário, e que essa premissa libertária precisa ser difundida em cada instância social;

a valorização da diferença - o respeito pela posição individual e a percepção de que é na discussão, muitas vezes de ideias divergentes, que a ação coletiva cresce;

a disseminação do conhecimento e o estímulo ao aprendizado - a preocupação em coletivizar os saberes dentro da organização, de modo que os indivíduos adquiram capacidades diversas;

HAAS, Marta. Criação coletiva como prática pedagógica: Experiências teatrais no Peru e no Brasil. Revista da FUNDARTE. Montenegro, p.01-19, ano 20, oㅡ 43, outubro/dezembro de 2020.

Disponível em: http://.seer.fundarte.rs.gov.br/index.php/revistadafundarte/index> 20 de dezembro de 2020. 


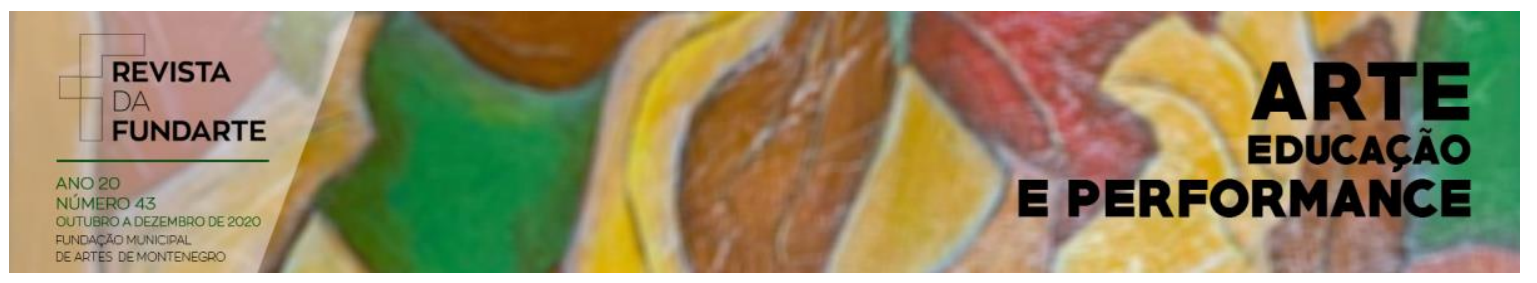

a significação do trabalho - estar ciente de que cada tarefa, das mais simples às arrojadas, é necessária, faz parte da construção de uma proposta em comum, independentemente de seu grau de complexidade; [...] a ênfase no trabalho corporal, pois a libertação do corpo, o dar condições para que se expresse, é parte essencial do processo de transformação social. (VECCHIO, 2007, p. 122-124).

Com base nessas observações, fica mais evidente como a noção de atuador, amplamente utilizada pelo grupo Ói Nóis Aqui Traveiz, pode comportar ensinamentos que vão desde a formação técnica do ator até outros âmbitos não tradicionais da pedagogia teatral, como por exemplo o engajamento social. Esses ensinamentos não são verdades fixas e imutáveis, não visam simplesmente imitar posturas e atos de um período datado, mas procuram sempre repensar, rediscutir e romper com os discursos prontos.

Miguel Rubio Zapata, ao falar sobre o impacto do conflito armado interno do Peru, e o trabalho com a Comissão da Verdade e Reconciliação (CRV) no trabalho do Yuyachkani2, afirma que houve no grupo uma "crise de representação", que os levou a um novo posicionamento em cena e fora dela. Segundo ele, nos primeiros anos, a maneira natural de se aproximar da criação teatral

\begin{abstract}
era inventando, trabalhando com temas e substituindo identidades. Quer dizer, assumindo representações não solicitadas. Desde que a primeira testemunha fala com voz própria ao mundo e dá conta de sua condição, eu sinto que se cancelam uma série de representações não solicitadas. A partir dali, incorporamos uma voz diferente no Yuyachkani, que é a do ator cidadão, do artista que também toma posição frente a seu próprio processo e encontra um lugar. Já não se trata de falar em nome da vítima e do afetado. Esse processo, para nós, foi determinante, pois nos perguntamos mais uma vez para que serve o que fazemos e que sentido tem. (ZAPATA apud GODOY, 2016, p. 17, tradução minha).
\end{abstract}

A reflexão sobre até que ponto estiveram assumindo representações (de camponeses, mineiros, migrantes) que, embora bem-intencionadas, não tivessem

\footnotetext{
2 O conflito armado interno no Peru, também denominado "guerra suja", compreende o período entre 1980 e 2000. Consiste num conflito extremamente violento entre governo e grupos guerrilheiros (Sendero Luminoso e Movimento Revolucionário Túpac Amaru). Ambos os lados foram responsáveis por mortes e graves violações dos direitos humanos, especialmente em zonas rurais no interior do país. Em 2001, houve uma grande mobilização da sociedade civil com o objetivo de pensar as consequências do conflito. É instaurada a Comissão da Verdade e Reconciliação (CVR), que fica encarregada de investigar os crimes e violações dos direitos humanos. O Yuyachkani faz parte dessa mobilização e acompanha com apresentações as audiências públicas e o lançamento do informe final da CVR.
}

HAAS, Marta. Criação coletiva como prática pedagógica: Experiências teatrais no Peru e no Brasil. Revista da FUNDARTE. Montenegro, p.01-19, ano 20, o 43, outubro/dezembro de 2020.

Disponível em: http://.seer.fundarte.rs.gov.br/index.php/revistadafundarte/index $>20$ de dezembro de 2020. 


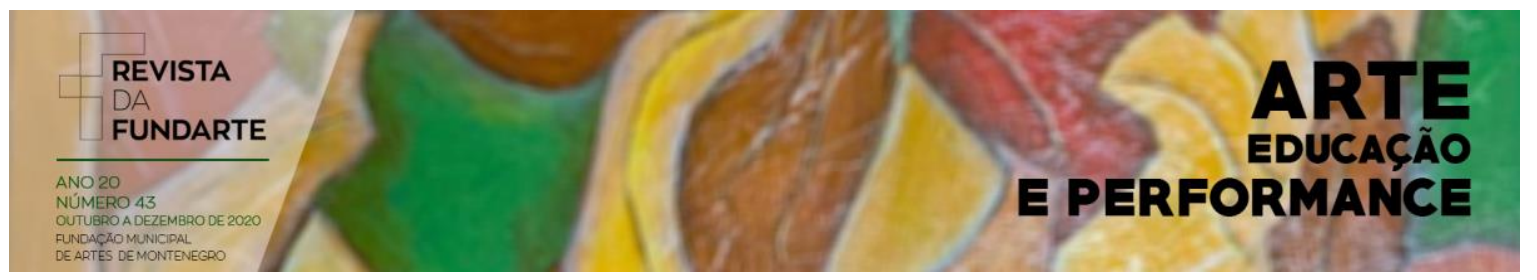

sido solicitadas, os levou a falar em seu próprio nome, com sua própria voz. Por trás disso está a ideia de que "o verdadeiro ativismo político está em ajudar a que todos tenhamos uma voz e que aqueles que não tenham voz, possam encontrá-la e falar com voz própria" (ZAPATA apud AGUILAR, 2013, p. 61). A partir dessa quebra, os membros do grupo falam a partir de sua própria condição de cidadãos, de como a situação de seu país Ihe afeta no âmbito pessoal. Ileana Diéguez (2008, p. 27) ressalta que esse modo de estar em cena e no espaço público é uma presença que assume compromissos éticos e borra limites entre arte e vida. $\mathrm{O}$ artista possui uma condição dual e seus atos são redimensionados, explicitando a dimensão ética que todo processo ou ato estético possui.

Quando penso no trabalho de um ator como intervenção cidadã penso na ação estética como ato do ethos, como ação comprometida com a vontade de sinalizar por meio do testemunho e da estratégia documental. O debatido problema da presença não só se refere a uma especificidade material, uma fisicalidade do ator que executa a partitura performativa. A presença abarca a eticidade do ato, a responsabilidade de estar num espaço cênico ou público, assumindo a intervenção como pessoa-artista-cidadão de seu tempo, com todos os riscos que supõe intervir no espaço público. (DIEGUEZ, 2008, p. 27, tradução minha).

Podemos, então, compreender melhor o que significa formar artistascidadãos, ideia presente na prática do Yuyachkani e implícita na própria noção de atuador do Ói Nóis. Formar-se ator implica uma relação de trabalho sobre si que extrapola o fazer teatral. Implica uma atitude ética, de reconhecer a sua responsabilidade como cidadão. No âmbito pedagógico, portanto, torna-se fundamental para os grupos formar atrizes e atores que, a partir de sua vivência e experiência singular, saibam reconhecer essas urgências do presente e possam reinventar em cada nova situação o que significa viver e ser artista no tempo e lugar que lhes coube.

Em seu programa de divulgação da Oficina Para Formação de Atores, o Ói Nóis costuma citar Barba (1991), ao abordar as relações entre teatro e revolução. Essa citação, de certa forma, sintetiza aquilo que o grupo acredita sobre o potencial transformador do teatro. A possibilidade de transformar-se depende de uma relação sincera e ética consigo mesmo, e é pressuposto da sua relação com os outros.

HAAS, Marta. Criação coletiva como prática pedagógica: Experiências teatrais no Peru e no Brasil. Revista da FUNDARTE. Montenegro, p.01-19, ano 20, no 43, outubro/dezembro de 2020.

Disponível em: http://.seer.fundarte.rs.gov.br/index.php/revistadafundarte/index> 20 de dezembro de 2020. 


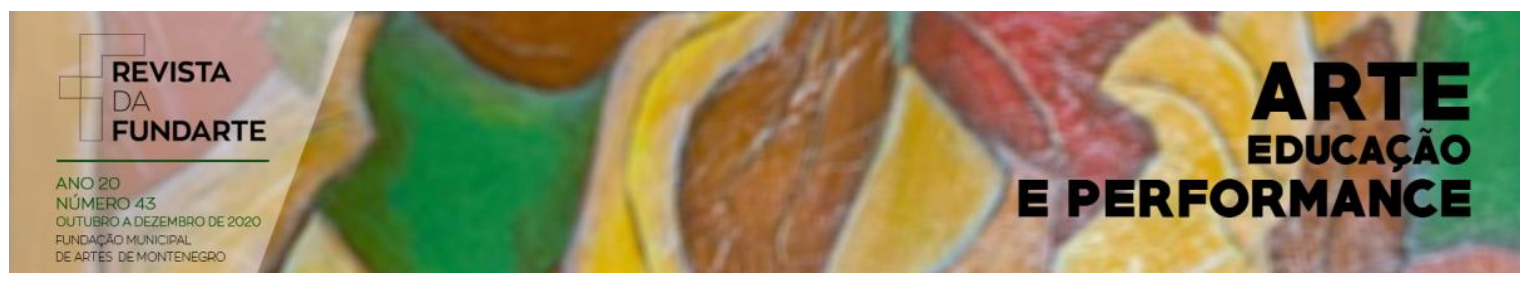

Nosso ofício é a possibilidade de mudar a nós mesmos e desse modo mudar a sociedade. Não é preciso perguntar-se: o que significa o teatro para o povo? Esta é uma pergunta demagógica e estéril. É preciso perguntar-se: o que significa o teatro para mim? A resposta, transformada em ação, sem compromissos nem precauções, será a revolução no teatro. (BARBA, 1991, p. 31).

\title{
A Tribo de Atuadores Ói Nóis Aqui Traveiz acredita que o teatro precisa ser
} um momento de encontro de pessoas, um momento de muita intensidade do qual se saia potencializado, transformando assim a vida de cada um e a sociedade como um todo. O Ói Nóis acredita que, por intermédio do teatro, podemos construir um ser humano solidário, consciente, aberto ao outro. Desde sua origem, o grupo dissemina ideias e práticas coletivas, de autonomia e liberdade, compartilhando a experiência de convivência e laboratório teatral. Para Rosyane Trotta,

\begin{abstract}
podemos concluir que as diversas instâncias de trabalho do grupo - ética, estética, pedagogia, técnica - são orientadas pelos mesmos princípios unificadores. O objetivo do processo criativo - e, também, do grande processo de constituir-se como grupo e como pessoa - reside na transformação. [...] Diferentemente da obra, que tem um trajeto definido e finito, o "ser coletivo" se prolonga no tempo e no espaço como subjetividade em permanente produção. Seu projeto ético-político propõe um outro modelo de sociedade, em que a participação possa dispensar a centralização. (TROTTA, 2008, p. 21).
\end{abstract}

Essa é a pedagogia do coletivo, presente nas ações artísticas e pedagógicas do Ói Nóis e Yuyachkani. Formar-se artista-cidadão implica um trabalho constante, seja externa ou internamente, na busca por transformação. A partir do encontro com o outro, da construção em grupo e comunidade, o processo contínuo de ação sobre si se revela formador de novas subjetividades. O processo de formação vai além do desenvolvimento de potencialidades individuais, ele se afirma como potência coletiva. Pensar coletivamente e agir em prol de um compromisso ético que se assume quando nos percebemos parte de um coletivo - seja o pequeno coletivo do grupo teatral, ou o grande coletivo que representa a nossa sociedade - talvez seja o principal ensinamento da criação coletiva, tal como colocada em prática pelo Yuyachkani e Ói Nóis. O compromisso com o coletivo, no qual existe uma

HAAS, Marta. Criação coletiva como prática pedagógica: Experiências teatrais no Peru e no Brasil. Revista da FUNDARTE. Montenegro, p.01-19, ano 20, no 43, outubro/dezembro de 2020.

Disponível em: http://.seer.fundarte.rs.gov.br/index.php/revistadafundarte/index $>20$ de dezembro de 2020. 


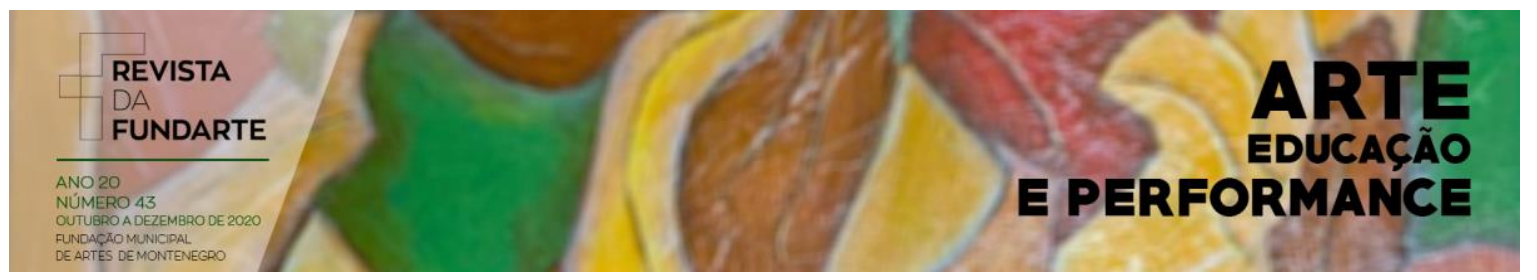

diversidade de experiências e saberes, estimula o pensamento crítico e resiste ao pensamento único e homogêneo.

A noção de pensamento único que trago aqui, remonta a discussão iniciada por Ignacio Ramonet, com a publicação do texto intitulado La pensée unique, no jornal Le monde Diplomatique, em 1995. Ramonet descreve o pensamento único como uma espécie de prisão, que suprime a liberdade de pensamento.

\begin{abstract}
Nas democracias atuais, cada vez mais cidadãos livres se sentem aprisionados, presos por um tipo de doutrina envolvente que, insensivelmente paralisa todos os espíritos rebeldes, inibindo-os, perturbando-os, paralisando-os e acabando por suprimi-los. Depois da queda do muro de Berlim, a derrocada dos regimes comunistas e a desmoralização do socialismo, a arrogância, a soberba e a insolência deste novo Evangelho atingiu um tal nível que pode-se, sem exagero, qualificar este furor ideológico de moderno dogmatismo. O que é o pensamento único? Tradução em termos ideológicos com pretensão universal das vantagens de um conjunto de forças econômicas, estas, em particular, do capital internacional. (RAMONET, 1995, p. 2).
\end{abstract}

O pensamento único, portanto, é uma visão social, uma ideologia, que se pretende exclusiva, natural, inquestionável. Para aqueles que sustentam 0 pensamento único, esse não é apenas um modo de ver a realidade, mas o único modo sensato de vê-la. Seu modelo seria amparado por um saber privilegiado e superior, por isso desqualifica todos os outros saberes. Embora esse pensamento com pretensão universal seja mais visível nos meios de comunicação de massa, e suas consequências se expressem, principalmente, no campo econômico e social, não se restringe a esses campos. O discurso do pensamento único, com sua pretensa superioridade, leva a aceitar determinados valores sem questioná-los, sem tencioná-los, diante de valores e posições alternativas. O pensamento único, portanto, condena todo pensamento crítico e divergente.

Delineada a noção de pensamento único, fica evidente que a prática de criação coletiva nos grupos Yuyachkani e Ói Nóis Aqui Traveiz, bem como seus pressupostos, contrapõem-se diretamente a ele. Ao invés de postular saberes privilegiados, os grupos apostam na diversidade de perspectivas. Ao invés de tratar determinados valores como naturais, questiona-se os mecanismos que perpetuam e

HAAS, Marta. Criação coletiva como prática pedagógica: Experiências teatrais no Peru e no Brasil. Revista da FUNDARTE. Montenegro, p.01-19, ano 20, oㅡ 43, outubro/dezembro de 2020.

Disponível em: http://.seer.fundarte.rs.gov.br/index.php/revistadafundarte/index> 20 de dezembro de 2020. 


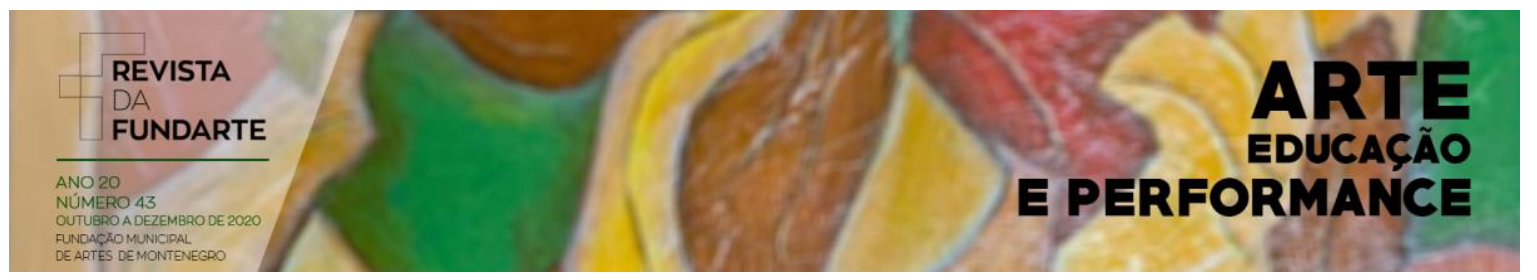

naturalizam esses valores. Ao invés de significados pré-fixados, a criação constante de novos sentidos. Pensar e agir num coletivo criativo e crítico pressupõe resistir ao pensamento único. Pressupõe justamente a divergência, a multiplicidade, a pluralidade, a heterogeneidade. Nesses grupos, portanto, a diferença não só é bemvinda, ela é condição para o próprio fazer coletivo.

\section{Referências:}

AGUILAR, Gina Monge. Trans-formação do ator no teatro de grupo em Latinoamérica: Abya Yala, Yuyachkani e Ói Nóis Aqui Traveiz. 2013. Doutorado em Artes Cênicas (Tese). Programa de Pós-Graduação em Artes Cênicas, Escola de Comunicação e Artes, Universidade de São Paulo, São Paulo, 2013.

ARAÚJO, Antônio. O processo colaborativo como modo de criação. Olhares: Revista da Escola Superior de Artes Célia Helena. Rio de Janeiro, n. 1, p. 48-51, 2009.

BARBA, Eugenio. Além das ilhas flutuantes. São Paulo: Ed. Hucitec, 1991.

DIÉGUEZ, lleana. Práticas de visibilidade: ethos, teatralidade y memoria. In ZAPATA, Miguel Rubio. El cuerpo ausente: performance política. Lima: Grupo Cultural Yuyachkani, p. 19-32, 2008.

GODOY, José Alejandro. Miguel Rubio Zapata: "No se puede dejar de pensar el arte separado de la vida". Memoria: revista sobre cultura, democracia y derechos humanos. Lima, n. 20, p. 16-21, 2016.

GRUPO CULTURAL YAYACHKANI. Teatro y comunidad. Lima, 2015. Disponível em: http://www.yuyachkani.org Acesso em: 06/12/2015.

FERNANDES, Sílvia. Grupos teatrais: anos 70. Campinas: Editora da Unicamp, 2000.

FISCHER, Stela. Processo colaborativo e experiências de companhias teatrais brasileiras. São Paulo: Editora Hucitec, 2010.

RAMONET, Ignacio. (1995). La pensée unique. Tradução de Jaerson Lucas Bezerra, maio/2011 Disponível em http://estrolabio.blogs.sapo.pt/1443984.html Acesso em 25/05/2017.

RAMOS, Luiz Fernando. Trajetórias alternativas do teatro nos anos 70: coincidências, sincronias e parentescos. In: Anos 70: trajetórias. São Paulo: 


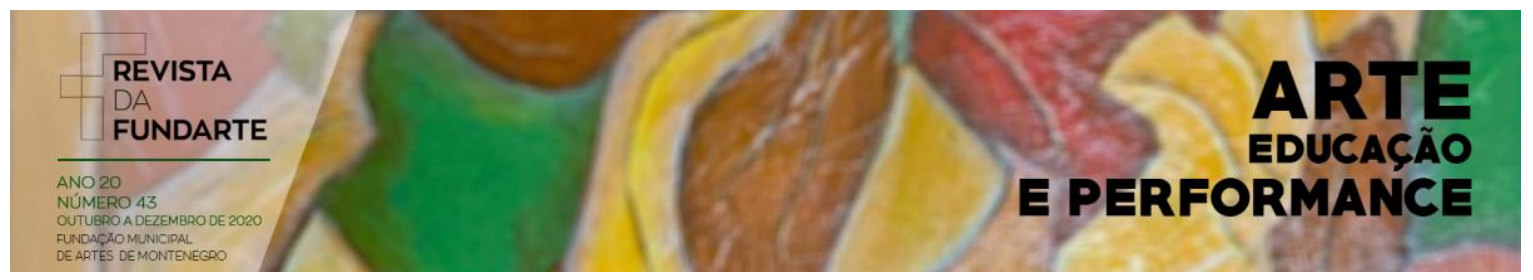

Iluminuras, p. 111-118, 2005.

RIZK, Beatriz J. Creación colectiva: el legado de Enrique Buenaventura. Buenos Aires: Atuel, 2008.

SILVA, Armando Sergio da. J. Guinsburg: diálogos sobre teatro. São Paulo: Edusp, 2002.

TROTTA, Rosyane. O Coletivo para além do Living Theatre. Cavalo Louco Revista de Teatro. Porto Alegre, n. 4, p. 16-21, 2008.

VECCHIO, Rafael. A utopia em ação. Porto Alegre: Ói Nóis na Memória, 2007.

ZAPATA, Miguel Rubio. Grupo, memoria y frontera. Revista Teatro/CELCIT. Buenos Aires, n. 34, p. 20-34, 2008.

ZAPATA, Miguel Rubio. Notas sobre teatro. Lima: Grupo Cultural Yuyachkani, 2001.

ZAPATA, Miguel Rubio. O teatro e nossa América. Urdimento: revista de estudos em artes cênicas. Florianópolis, n. 22, p. 259-266, 2014. 